\title{
Helping or Hindering? How Clients' Experiences Relate to Their Robo Advisory Use
}

\author{
Anke Schulz \\ LMU Munich \\ schulz@1mu.de
}

\author{
Anja Tuschke \\ LMU Munich \\ tuschke@bwl.lmu.de
}

\author{
Alexander Ilgen \\ Deutsche Bank AG \\ Alexander.Ilgen@db.com
}

\begin{abstract}
Firms are increasingly introducing new business models based on digital technologies in knowledgeintensive, risky contexts that were long immune to them. In the financial industry, banks are opening themselves to robo advisory, an algorithm-based service supporting private clients' investment decisions. Based on our access to a recent data set of 11,302 clients from a leading German robo advisory provider, we have the unique opportunity to analyze how clients react to algorithm-based services in contexts with high uncertainty and risk. Guided by theorical foundations of knowledge and routines, we find clients' personal and business experiences with the focal bank to both, help and hinder their robo advisory use.
\end{abstract}

\section{Introduction}

Firms across various business contexts are offering additional services based on algorithms [1-3]. These algorithms transform existing business models, helping firms to offer existing services at lower cost. More recently, algorithm-based digital transformation has spread to new cost- and knowledge-intensive service areas in which clients face high personal risk [4-5], as in banking for private clients. Here, an important transformation of extant banking service is based on robo advisory, which provides clients with the option to rely on algorithms rather than bank advisors to actively manage their personal investment decisions.

Large streams of research have looked into how individuals respond to digital technologies [6-11], and more recently algorithms [12]. While theses studies offer valuable insights of how users react to algorithms in making relatively "safe" decisions - i.e., those surrounding which either risk is low or technology is better understood - less is known about how clients respond to a service like robo advisory in a real-world setting. Other than an experiment, private shopping purchase, or work assignment gone wrong, unfortunate investment decisions put clients' personal wealth at risk Our study aims at providing deeper insights into what opens clients to use algorithm-based services in knowledge-intensive, risky contexts by investigating the case of robo advisory in banking.

Before the introduction of robo advisory, the amount of professional investment advice that clients received could easily be distinguished according to their investment volume. Clients with a considerably low investment volume could either make decisions on their own or approach bank professionals to discuss investment alternatives. In contrast, clients with a considerably high investment volume had the additional option to receive bank advisors' active portfolio advice (APA) on their investment decisions. Robo advisory is equivalent to APA with two notable differences: First, in the case of robo advisory, algorithms instead of humans actively support clients' investment decisions. Second, as the costs of providing robo advisory are substantially lower than those of providing APA, clients can access the digitalized service at a much lower investment threshold.

Tested and validated by the market, robo advisory enables broad strata of clients to receive active support on their investment decisions. Despite its many advantages, however, many clients can be expected to shy away from a digital format like robo advisory as it also leads to trepidations. First and foremost, clients have to overcome the well-documented algorithm aversion [13], i.e., their concerns about "trusting" the advice of algorithms. In addition, they have to break with established habits and routines [14-15]. Finally, clients need to be open to a new digital advisory format that requires them to take on greater responsibility. They need to face not only their own knowledge gaps, but also their inability to "scapegoat" misplaced investment decisions, as they rather than their bank advisors must feed and track the robo advisor [16].

Building on a recent dataset of 11,302 private clients of an important robo advisory provider as well as insights from seven in-depth interviews with bank advisors, we analyze how clients' characteristics relate 
to their robo advisory use. By using client data from the time frame before robo advisory was actively marketed by the focal bank under study - i.e., when bank advisors were prohibited from proactively approaching clients on the new service unless clients themselves reached out for information - we provide unique, real-world insights into the behavioral drivers behind clients' robo advisory use.

Guided by theoretical foundations of the behavioral decision-making [14-15] and learning literature [17-19] we consider particularly how clients' personal and business experiences at the focal bank - the basis of their robo advisory-aligned or -misaligned knowledge and routines - guide their usage decisions. First, we expect clients with longer history at the focal bank to be less open to use robo advisory. We assume that these clients have stronger routines in personal interaction with bank professionals that conflict with robo advisory use. In contrast, we assume clients having a high investment volume at their disposal to be more familiar with receiving advice. Therefore, we expect such wealthier clients to be more open towards using robo advisory than less wealthy clients. Third, we argue that clients who recently invested themselves - and with that, accessed first-hand investment information - are more open towards robo advisory based on having greater relevant knowledge.

Our study contributes to extant literature in several ways. Besides information systems [13,] [20], there is a growing literature in management [21], [12], [5] and strategy (e.g. [22]) interested in the changes that algorithms and predictive analytics are inducing for firms, particularly in knowledge-intensive contexts. Complementing existing work considering e.g. how algorithms reshape firms' internal sourcing or resource allocation decisions, we provide a client perspective on who uses robo advisory. Our findings resonate with the well-documented relevance of individual experience in shaping strategically relevant outcomes for firms [2325]. They suggest that clients opting for algorithmbased services in contexts characterized by high uncertainty and risk base their decisions on knowledge and routines formed at their service providers. As such knowledge and routines may be more aligned or misaligned with a new algorithm-based service like robo advisory, they can both, help and and hinder its use.

\section{Theoretical Background}

Individuals are generally biased against using digital technologies. Studies on online banking [26-29] show that clients are concerned about using digital technologies, even when they have considerably low personal risk. Users worry not only about the security and privacy
[30], [27], [31] but also about the reliability [32] of such technologies. Lack of personal interaction may further enhance clients' discomfort [33-34]. Discomfort is especially pronounced if these new technologies are based on algorithms [13], [35-36].

"Algorithm aversion", i.e., individuals' greater uneasiness to trust algorithms [13], is a widely observed phenomenon even under conditions in which these algorithms clearly outperform the decision-making of their human counterparts [35], [37]. Conditions in which algorithms make superior decisions to humans can be found in contexts with weak and uncertain cues, i.e., lower predictability. Knowledge-intensive contexts like banking have long been recognized to have such conditions [38]. A bank branch manager interviewed for our study describes how the unpredictability of the context has only increased over time: "Investment decisionmaking has become so broad and affected by a flood of information, Mr. Trump twitters something and all the markets respond [immediately], it is nearly impossible to react so fast. Even as a bank advisor, you are active in many professional fields, you have things that you do at once, so that you cannot stay up to date on everything. Thank God that we have [back offices]."

The introduction of robo advisory is only a recent phenomenon. Against this background, many clients can be expected to face strong trepidations in relying on algorithms. While individuals are generally known to have a strong tendency to avoid losses, despite high potential gains [39], they can be expected to be even more concerned in entrusting a very novel and unfamiliar technology with investment decisions regarding their personal wealth. Our interviews with bank advisors in Appendix 1 highlight client concerns ranging from performance of algorithms (Interview 3) to the vulnerability of robo advisory to hacking (Interview 2).

While many studies surrounding how users respond to digital technologies build on the Technology Acceptance Model, these studies focus on settings in which users face low personal risk, e.g. experiments, work assignments, or online shopping [6-11]. Additionally, such studies often regard less novel technology applications than robo advisory like online banking. Based on their lower levels of technical advance, such technologies often support clients by informing rather than executing actions on their behalf. Not surprisingly, as their usage contexts and application areas raise fewer questions and concerns, users have been found to consider mainly their benefits and perceived ease of use when assessing attractiveness.

Usage considerations relating to very novel, risky technology-based services like robo advisory can be expected to be very different. Clients have long been long known to struggle with, or even delay, usage decisions when they lack information concerning new options at 
their disposal [40]. With very low existing information to build upon, we expect those clients opting for robo advisory to base their decision on prior experiences formed at their service provider, in our case, the focal bank under study. While prior experiences - or better, the knowledge and routines resulting from them - may be more aligned or misaligned with robo advisory use, they represent the closest approximation that clients can leverage in assessing the attractiveness of such a novel, risky service.

Figure 1 provides an overview of our model that links clients' history with the focal bank (suggesting stronger routines misaligned with robo advisory use), their investment volume (proposing stronger routines aligned with robo advisory use), and recent first-hand investment information access (suggesting greater knowledge aligned with robo advisory use) to their likelihood of using algorithm-based portfolio advice.

\begin{tabular}{|l|l|l|}
\hline $\begin{array}{l}\text { Client History } \\
\text { (Years) }\end{array}$ & $\begin{array}{c}\text { Routines } \\
\text { misaligned with } \\
\text { robo advisory use }\end{array}$ \\
\hline $\begin{array}{l}\text { Investment Volume (in } \\
10,000 \text { Euros) }\end{array}$ & $\begin{array}{l}\text { Routines aligned } \\
\text { with robo } \\
\text { advisory use }\end{array}$ \\
\hline $\begin{array}{l}\text { Intensity of First-Hand } \\
\text { Investment Information } \\
\text { Access (Six Month Periods) }\end{array}$ & $\begin{array}{l}\text { Knowledge aiding } \\
\text { robo advisory use }\end{array}$ \\
\hline
\end{tabular}

Figure 1. Conceptual model of clients' likelihood of robo advisory use

We form the following hypotheses.

\section{Client History and Robo Advisory Use}

In knowledge-intensive, risky contexts such as banking, clients interact very closely and regularly with professionals such as bank advisors. One main reasons is that professionals in such contexts possess very high domain-specific knowledge and skills, surpassing not only that of most clients, but even their own managers [41]. While personal interactions are generally high in banking, some clients can be expected to have accumulated more dealings than others.

Particularly clients with longer client history can be expected to have accumulated great numbers of personal interactions with bank professionals, based on their longer time at the bank. Research on behavioral decision-making has long highlighted the central role that habits and routines play in shaping individuals' actions and decisions [14-15]. While individuals generally dislike breaking with the comfort that habits and routines offer, they do so even more when they are reinforced over time. Accordingly, we expect routines in personal interaction to be particularly strong amongst clients with more client years.
Not only habits and routines, but also trust is known to intensify with interaction history [3], [43-46]. Our interviews with bank advisors in Appendix 2 illustrate how clients share more personal information and feelings with them, the longer their stay at the bank (Interview 3, Statement 1). Over the course of their client history, clients develop trust relationships with their advisors (Interview 3, Statement 1). Such trust relationships tend to increase clients' satisfaction with existing service. Clients' decision to stay at the bank, despite low switching costs to alternative service providers, is one reflection of the value that these relationships have (Interview 4, Statement 1).

Clients are known to resist innovations which require a change in their existing habits and routines [4748] or a current situation with which they are satisfied [49-51]. Arguing that client history is the source of both, we expect clients with a longer history at the focal bank to be less likely to use robo advisory than those with a shorter stay. We assume that former clients will be more inert to switch from their trusted and appreciated personal relationships to receiving investment advice from algorithms. In summary, we expect routines in personal interaction to be misaligned with robo advisory use. We hypothesize:

Hypothesis 1: The longer clients' history with the focal bank, the lower their likelihood to use robo advisory.

\section{Investment Volume and Robo Advisory Use}

Scholars have observed clients to respond differently to innovations based on their financial situation [47], [52-53]. In line with that, we expect clients having higher investment volumes to show different reactions to robo advisory than those with lower ones. One main reason is that we expect clients with different wealth levels to have very dissimilar routines regarding the use of investment services. These services - particularly those offering higher support on investment decisions like APA - require clients to meet certain investment thresholds. For example, clients need to invest a minimum volume of $€ 250,000$ to access APA at the focal bank under study. Such high investment thresholds are the reason why portfolio advice was long restricted to the wealthy elite before the introduction of robo advisory [54].

As less wealthy individuals were long excluded from accessing supportive services based on low investment volume, they could not form habits and routines in receiving high investment advice from financial advisors comparable to their wealthier counterparts. Also, their exposure to information on personal services comparable or equivalent to robo advisory, such as APA, was lower. In summary, while all clients can be expected to be unfamiliar with having a digital advisor supporting 
their investment decisions, wealthier clients can be assumed to be more acquainted with and/or be better informed about receiving higher levels of (personal) investment support than less wealthy ones. Less wealthy clients, on the other hand, need to familiarize with both, algorithms as well as receiving extensive support on investment decisions. Having less transferable experience, we assume robo advisory to appear more novel and unfamiliar to them.

Individuals are known to be biased against options they perceive as less familiar when making decisions [55-57]. Considering this and the previously introduced theoretical foundation of sticking to habits and routines [14-15], we assume clients with higher investment volume to be more open to use robo advisory. Thus, we hypothesize:

Hypothesis 2: Clients with higher investment volume are more likely to use robo advisory than clients with lower investment volume.

\section{Recent Investment Information Access and Robo Advisory Use}

In the case of robo advisory, relying on the support of a digital rather than a personal portfolio advice goes hand-in-hand with clients needing to feed, track, and correct investment decisions of algorithms. To do so, clients need certain knowledge and skills on investment decision-making. Based on clients' novel access to algorithm-based services, but also the long-known volatility characterizing knowledge-intensive contexts [38], we consider clients' recent access to first-hand investment information to be particularly useful in this regard.

First-hand information - i.e., information that individuals gain directly through own experience rather than through the experience of others - is a widely recognized enhancer of individual knowledge [19], [58]. In banking, clients gain such knowledge by taking care of their investments themselves rather than relying on the knowledge of their bank advisors. While bank advisors' knowledge on investment decision-making may often surpass that of their clients [41], clients, not bank advisors, bear the responsibility of feeding and monitoring their robo advisor. By investing on their own prior to using robo advisory, clients learn to set up their own trading accounts, invest their own money along their risk preferences and follow the development of their investments over the internet. Such first-hand information automatically increases clients' ability to use robo advisory. Additionally, clients may become confronted with their own, human limitations in investment decisionmaking [35], [37] and with that, recognize the opportunity that decision support by algorithms entails.

Accordingly, we expect clients with recent access to such first-hand investment information to be more open to using robo advisory. We argue that the depicted firsthand investment information is the basis for building relevant knowledge and skills for using robo advisory. Thus, we hypothesize:

Hypothesis 3: Clients with first-hand investment information access are more likely to use robo advisory than clients without first-hand access.

\section{Data and Method}

We test our hypotheses using a data set of 11,302 private clients provided by a leading German bank. Based on its economic, technological, and financial leadership, the German context is comparable to other major economies, including much larger markets like the United States. Both countries are among the world's top ten economies, with the United States ranking 85.6 and Germany ranking 82.8 on the global competitive index, which ranges from 0 to 100 [59]. Regarding the market for private investment services, Germany is dominated by only few banks [54], one of which is the bank under study. While robo advisory is a young but developing field in Germany, the quality of the respective models on the market for private clients can be considered as very high. As consumer protection is a key societal concern, only excellent robo advisory services are released on the market. Not surprisingly, rigorous testing and performance monitoring pre and post market introduction accompany all robo advisory launches. The quality of the robo advisory model under study has been tested by the most important consumer protection agency in Germany, scoring amongst the top three overall ratings [60].

The model became available to private clients of the focal bank in early 2018 and its characteristics are similar to other robo advisory models in the market. To account for potential time lags in the decision-making of clients, we matched data on client characteristics from late 2017 with clients' investment choices (i.e., using robo advisory or not) in 2018. Using data from the early time of robo advisory introduction has two advantages for our analyses. First, it excludes that our results capture implications of organizational restructuring rather than client behaviors. Afterall, the number of investment services and/or bank advisors is not adapted to the introduction of a new service at such an early stage. Second, the time frame of our analysis rules out that bank advisors rather than clients are steering their use of robo advisory. In 2017, bank advisors were not allowed to proactively approach clients about robo advisory in advisory sessions.

Our random sample covers both the entire spectrum of clients and all investment services available to them 
at the bank under study. Amongst all investment services provided, robo advisory is the only digital format that clients can choose. We include only clients that have the choice to use robo advisory in our sample. Specifically, as the investment threshold for qualifying for robo advisory at the focal bank is $€ 5,000$, we consider only clients with an investment volume equal or above this threshold in our analyses. Also, in consultation with industry experts, we include only first-time APA users in our sample, to exclude the possibility that systematic differences in characteristics of first-time and repeated users of active investment support impact our results. Put differently, all clients in our sample are not only using robo advisory, but also its personal equivalent APA for the first time in 2018. To complement our theory building and understanding of empirical findings with insights from our institutional setting, we conducted seven in-depth expert interviews with bank advisors. We chose advisors based on their years of work experience with private clients, both at the focal bank and/or in other banks, and their familiarity with robo advisory (Appendix 3). The telephone interviews lasted on average 40 minutes and were conducted in late August 2018.

Our empirical analyses include the following measures. Our dependent variable Robo Advisory is a dummy variable taking on the value of one if a client uses robo advisory and zero if s/he uses alternative investment services. Our two independent variables concerning routines are operationalized as follows. $\mathrm{Cli}$ ent History (Years) is a variable indicating the number of years an individual has been a client at the focal bank. A client history of 0 indicates that the client joined the bank in 2017. Investment Volume (in 10,000 Euros) indicates the total amount of liquid assets that the client has available for investment decisions both, in savings accounts and investment deposits at the focal bank. Investment volume data is winsorized at the $1 \%$ and $99 \%$ level in all analyses. While we choose a linear specification of this key variable in our main analyses to provide readers with a straight-forward interpretation of its effect, our robustness tests covered and confirmed also its logarithmic specification. Our independent variable reflecting knowledge, Intensity of First-Hand Investment Information Access (Six Month Periods), is a variable indicating the number of six month periods before January 2018 in which the client accessed investment information through own investment activity in the previous year. We include socio-demographic control variables in our empirical analyses. Female is a dummy variable taking on the value of one if the client is female and zero if he is male. The client's age is measured in years. Age data is winsorized at the $1 \%$ and $99 \%$ level in all analyses. $\operatorname{Ln}($ Income +1$)$ is the natural logarithm of the client's income plus one. We proxy for clients' digital affinity by their previous online banking activation.
The latter is a dummy variable taking on the value of one if the client has activated online banking at the focal bank and zero if not. Lastly, we account for differences in clients' advisor information access by a dummy variable measuring whether or not they used high investment decision support services in the previous year. In doing so we consider that certain clients may have had a higher opportunity to proactively seek information on robo advisory through advisors based on their service structure.

Regarding our method, we follow existing literature [61], in employing a linear probability model (LPM) to estimate the impact of our chosen client characteristics on clients' likelihood of using robo advisory. We also estimate other functional forms with non-linear response probabilities. All results are depicted in Table 2. Whereas the R-Squared in the LPM represents the ordinary least squares (OLS) R-Squared, the Pseudo Rsquared in our probit and logit models is based on loglikelihood measures. As the marginal effects revealed by the probit and logit specifications compare to their LPM counterparts, we interpret only LPM coefficients. We further interpret odds ratios of our logistic regression effects to provide insights into the economic significance of our results.

\section{Results}

Our descriptive analyses point to large differences in who uses robo advisory. Table 1 shows the descriptive statistics and correlations for our full sample. Both, clients' investment volume $(r=0.118, \mathrm{p}=0.000)$ and their intensity of first-hand information access $(\mathrm{r}=0.450$, $\mathrm{p}=0.000$ ) are significantly positively correlated with robo advisory use, while their client history is significantly negatively correlated $(\mathrm{r}=-0.070, \mathrm{p}=0.000)$. Table 2 presents the results of our full sample regression analyses. Models 1 to 3 show the impact of the control variables on the likelihood of using robo advisory. Models 4 to 6 depict the results of the control variables and the independent variable Client History (Years). The following Models 7 to 9 show the results of the control variables and the second independent variable Investment Volume (in 10,000 Euros). Thereafter, Models 10 to 12 present the results of the control variables and the third independent variable First-Hand Investment Information Access (Six Month Periods). Finally, models 13 to 15 show the results of the full model. For an economic interpretation, we report effect sizes in the form of odds ratios of Model 15 in the second-last column. 
Table 1. Regressions on likelihood to use robo advisory for all clients, DV=Robo Advisory

\begin{tabular}{|c|c|c|c|c|c|c|c|c|c|c|c|c|c|}
\hline Variables & Mean & S.D. & Min & Max & 1 & 2 & 3 & 4 & 5 & 6 & 7 & 8 & 9 \\
\hline 1 Robo Advisory & 0.09 & 0.28 & 0 & 1 & & & & & & & & & \\
\hline 2 Client History (Years) & 19.37 & 12.50 & 0 & 64 & $-0.070^{*}$ & & & & & & & & \\
\hline 3 Investment Volume (in Euros) & $83,158.16$ & 162635.80 & 5118 & $1,036,615$ & $0.118^{*}$ & $0.042^{*}$ & & & & & & & \\
\hline 4 Intensity of First-Hand Investment Information Access (Six Month Periods) & 0.21 & 0.61 & 0 & 2 & $0.450^{*}$ & $-0.091^{*}$ & $0.134^{*}$ & & & & & & \\
\hline 5 Female & 0.41 & 0.49 & 0 & 1 & $-0.180^{*}$ & -0.003 & $-0.051^{*}$ & $-0.159^{*}$ & & & & & \\
\hline 6 Age & 54.90 & 18.02 & 11 & 91 & $-0.101^{*}$ & $0.408^{*}$ & $0.169^{*}$ & $-0.100^{*}$ & $0.084^{*}$ & & & & \\
\hline 7 Ln[Income(in Euros)+1] & 5.02 & 4.07 & 0 & 15 & $0.077^{*}$ & $0.219^{*}$ & $0.062^{*}$ & $-0.068^{*}$ & $-0.075^{*}$ & $-0.087^{*}$ & & & \\
\hline 8 Online Banking Activation & 0.67 & 0.47 & 0 & 1 & $0.204^{*}$ & $-0.159^{*}$ & $0.042^{*}$ & $0.206^{*}$ & $-0.179^{*}$ & $-0.361^{*}$ & $0.322^{*}$ & & \\
\hline 9 High Advisor Information Access & 0.34 & 0.47 & 0 & 1 & -0.004 & $0.042^{*}$ & $0.271^{*}$ & $-0.108^{*}$ & -0.012 & $0.139^{*}$ & $-0.198^{*}$ & $-0.052^{*}$ & \\
\hline $\mathrm{N}$ & & & & & 11,302 & & & & & & & & \\
\hline
\end{tabular}

Table 2. Regressions on likelihood to use robo advisory for all clients, DV=Robo Advisory

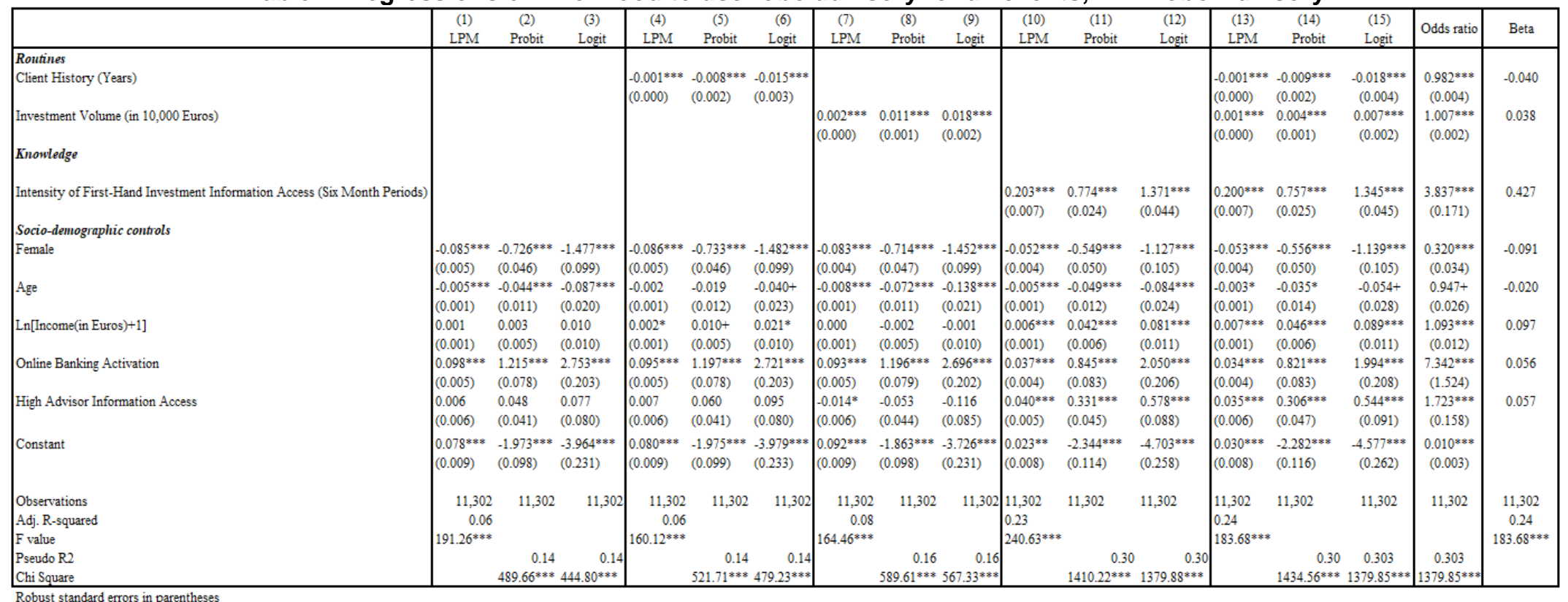

Robust standard errors in parentheses 
Odds ratios indicate how a change in our independent variables - i.e., Client History (Years), Investment Volume (in 10,000 Euros), and First-Hand Investment Information Access (Six Month Periods) - alters the odds for the occurrence of the event of using robo advisory. For robustness, the last column in Table 2 depicts the beta-coefficients of our main model 13, based on the (z-)standardization of all regression variables. As betacoefficients are unitless - i.e., they refer to how many standard deviations the dependent variable changes per unit standard deviation increase in our independent and control variables - they ensure that differences between our reported effect sizes are not driven by differences in measurement scales of our predictors.

While we find support for our hypotheses in all models and model specifications, our results indicate particularly strong support for hypothesis 3. Results of our main model (Model 13) suggest that an additional six month period of recent, first-hand investment information increases clients' probability of using robo advisory by $0.20(\mathrm{p}=0.000)$. The odds ratio of Intensity of First-Hand Investment Information Access ((Six Month Periods) is 3.837 ( $\mathrm{p}=0.000)$, indicating that an additional six month period of recent investment information access increases a client's odds to use robo advisory by over 300 percent. Our results for Client History (Years) suggest that each additional year of client history reduces the probability and odds to use robo advisory significantly, but only marginally. Specifically, clients' probability of using robo advisory decreases by $0.001(\mathrm{p}=0.000)$, while their odds of using robo advisory fall by two percent $(\mathrm{p}=0.001)$ with each year at the focal bank. Lastly, our results for Investment Volume (in 10,000 Euros) indicate similar, yet opposite effects in comparison to our previous predictor variable. They suggest that with each additional 10,000 Euros of investment volume, clients' probability of using robo advisory increases by $0.01(\mathrm{p}=0.01)$. The odds ratio of 1.007 $(\mathrm{p}=0.000)$ indicates that clients' odds of using robo advisory raise by one percent with every 10,000 Euros that they invest at the bank.

We ran various robustness tests to build confidence in our findings ranging from regressions with log-transformed investment volume measures to ones allowing for differences in effects between APA-qualified and -unqualified users. All robustness tests supported our results, highlighting particularly the centrality of firsthand investment information, gained through own investment experience, in opening clients towards robo advisory - as do the beta coefficients in Table 2 .

\section{Discussion and Conclusion}

The objective of our paper was to investigate how clients respond to the recent introduction of a new service providing algorithm-based investment advice robo advisory in banking. Drawing on insights from a rich, large-scale data set of bank clients and interviews with bank advisors, we explored what drives the decision to rely on digital services in a knowledge-intensive, risky context. We find support for our hypotheses that clients' history with the focal bank, investment volume, and intensity of first-hand investment information access influence the likelihood of using robo advisory. While all three factors are significant, we find that clients' intensity of first-hand investment information access has by far the strongest impact on their use of robo advisory.

Theoretical insights and empirical results of our study primarily speak to the behavioral literature in management [62-63], information systems [13], [20], psychology [64-67], and finance [68]. We present both, main challenges that algorithm-based digital services in knowledge-intensive, risky settings face on the client side and ways to overcome them. In settings in which clients have especially strong reservations about using algorithm-based services despite the high advantages and new opportunities they offer understanding how users can overcome their trepidations and use services like robo advisory is of crucial interest to many parties. One main group are scholars interested in how individuals can improve boundedly rational decision-making [69], particularly in the context of new technology use [13], [20]. Our analysis of a large, real-world data set allows us to provide insights on the behavioral drivers of clients' use of algorithm-based services that complement those documented by studies in less risky decision contexts, e.g. experiments. We find that in contexts characterized by high uncertainty and risk, users' experiences with their service providers - the foundation for knowledge and routines aligned and misaligned with technology use - are central in driving their adoption decisions. Our results suggest that while existing routines may make clients slightly more or less open towards robo advisory, gaining first-hand information aligned with using algorithm-based services is a game changer when it comes to raising openness of clients.

There are several limitations to this study, which provide room for future research. First and foremost, our study on the behavioral drivers behind clients' robo advisory use necessarily relies on cross-sectional data referring to the time before its introduction. While this focus allows us to rule out the impacts of organizational restructuring or marketing campaigns on our results, it raises other concerns. First, our data is subject to potential unobserved heterogeneity biases, which prevent us from inferring causal relationships from our analyses. Also, it constrains us in exploring additional, promising research questions - such as interaction effects between client characteristics - as it limits the number of observations available for respective subgroup analysis. Our analyses and interviews provide some comfort on these concerns. While individual characteristics of users may never be fully independent from one another, correlation 
coefficients between observable characteristics in Table 1 take on common magnitudes. Also, our detailed interviews with various industry experts working in the relevant institutional field support our results. We welcome and encourage future research to replicate and extend our findings in different knowledge contexts, using longitudinal data. A second main limitation of our study is that we can only provide insights into clients' extensive, not intensive, use of investment services. Based on the very recent introduction of robo advisory in the bank under study, the largely personal format of investment services, as well as German data protection laws, it is very difficult - if not impossible - to gather representative data on how frequently clients use investment services.

Our study yields important practical implications by revealing which clients find robo advisory attractive. Primarily, our results can help bank advisors improve their recommendations to clients. In their daily business, many bank advisors still rely on largely theoretical concepts on how clients respond to digital technologies to guide their service and recommendations. While such a bottom-up approach may be very valuable in general, it is subject to limitations when used to understand reactions to new digital formats like robo advisory. By inferring who uses robo advisory through analyzing a large data set, we offer real world insights into this question. Our study introduces a new business case on robo advisory that can inform and inspire other firms, in particular banks, in the field.

\section{References}

[1] Grove, W. M., \& Meehl, P. E. 1996. Comparative efficiency of informal (subjective, impressionistic) and formal (mechanical, algorithmic) prediction procedures: the clinicalstatistical controversy. Psychology, Public Policy, and Law, 2(2): 293-323.

[2] Koren, Y., Bell, R., \& Volinsky, C. 2009. Matrix factorization techniques for recommender systems. Computer, 42(8): 30-37.

[3] Meehl, P. E. 1954. Clinical Versus Statistical Prediction: A Theoretical Analysis and a Review of the Evidence. Minneapolis, MN: University of Minnesota Press.

[4] Brynjolfsson, E., \& McAfee, A. 2017. The business of artificial intelligence. Harvard Business Review, 7: 1-20.

[5] Raisch, S., \& Krakowski, S. 2020. Artificial Intelligence and Management: The Automation-Augmentation Paradox. Academy of Management Review, 46(1), 192-210.

[6] Davis, F. D. 1989. Perceived usefulness, perceived ease of use, and user acceptance of information technology. MIS Quarterly, 13(3): 319-340.

[7] Davis, F. D., Bagozzi, R. P., \& Warshaw, P. R. 1989. User acceptance of computer technology: a comparison of two theoretical models. Management Science, 35(8): 982-1003.

[8] Hong, W., Thong, J. Y., Wong, W.-M., \& Tam, K.-Y. 2002. Determinants of user acceptance of digital libraries: an empirical examination of individual differences and system characteristics. Journal of Management Information Systems, 18(3): 97-124.
[9] Schierz, P. G., Schilke, O., \& Wirtz, B. W. 2010. Understanding consumer acceptance of mobile payment services: an empirical analysis. Electronic Commerce Research and Applications, 9(3): 209-216.

[10] Venkatesh, V., \& Davis, F. D. 2000. A theoretical extension of the technology acceptance model: four longitudinal field studies. Management Science, 46(2): 186-204.

[11] Venkatesh, V., Morris, M. G., Davis, G. B., \& Davis, F. D. 2003. User acceptance of information technology: toward a unified view. MIS Quarterly, 27(3): 425-478.

[12] Jago, A. S. 2019. Algorithms and authenticity. Academy of Management Discoveries, 5(1): 38-56.

[13] Dietvorst, B. J., Simmons, J. P., \& Massey, C. 2015. Algorithm aversion: people erroneously avoid algorithms after seeing them err. Journal of Experimental Psychology: General, 144(1): 114-126.

[14] Cyert, R. M., \& March, J. G. 1963. A Behavioral Theory of the Firm. Englewood Cliffs: Prentice-Hall.

[15] Nelson, R. R., \& Winter, S. G. 1982. An evolutionary theory of economic change. Harvard University Press: Cambridge.

[16] Gamson, W. A., \& Scotch, N. A. 1964. Scapegoating in baseball. American Journal of Sociology, 70(1): 69-72.

[17] Argote, L. 1999. Organizational learning: Creating, retaining and transferring knowledge. Springer Science \& Business Media: New York.

[18] Argote, L., \& Epple, D. N. 1990. Learning curves in manufacturing: Carnegie Mellon University, Graduate School of Industrial Administration.

[19] Argote, L., \& Miron-Spektor, E. 2011. Organizational learning: From experience to knowledge. Organization Science, 22(5): 1123-1137.

[20] Dietvorst, B. J., Simmons J. P., \& Massey, C. 2016. Overcoming algorithm aversion: people will use imperfect algorithms if they can (even slightly) modify them. Management Science, 64(3):1155-1170.

[21] Amabile, T. 2019. GUIDEPOST: Creativity, Artificial Intelligence, and a World of Surprises. Guidepost Letter for Academy of Management Discoveries. Academy of Management Discoveries, 6(3): 351-354.

[22] Elfenbein, D. W., \& Sterling, A. D. 2018. (When) Is hiring strategic? Human capital acquisition in the age of algorithms. Strategy Science, 3(4): 668-682.

[23] Edmondson, A. C., \& Nembhard, I. M. 2009. Product

development and learning in project teams: the challenges are the benefits*. Journal of Product Innovation Management, 26(2): 123-138.

[24] Reagans, R., Argote, L., \& Brooks, D. 2005. Individual experience and experience working together: Predicting learning rates from knowing who knows what and knowing how to work together. Management Science, 51(6): 869-881.

[25] Storbacka, K., Brodie, R. J., Böhmann, T., Maglio, P. P., $\&$ Nenonen, S. 2016. Actor engagement as a microfoundation for value co-creation. Journal of Business Research, 69(8): 3008-3017.

[26] Orr, B. 2001. E-banking: what next? American Bankers Association. ABA Banking Journal 93(12): 40.

[27] Pikkarainen T, Pikkarainen K, Karjaluoto H, Pahnila S. 2004. Consumer acceptance of online banking: an extension of the technology acceptance model. Internet Research 14(3): 224-235.

[28] Sheshunoff A. 2000. Internet banking - an update from the frontlines. American Bankers Association. ABA Banking Journal 92(1): 51-55. 
[29] White, H., Nteli, F. 2004. Internet banking in the UK: why are there not more customers? Journal of Financial Services Marketing 9(1): 49-56.

[30] Howcroft B., Hamilton, R., Hewer, P. 2002. Consumer attitude and the usage and adoption of home-based banking in the United Kingdom. International Journal of Bank Marketing 20(3):111-121.

[31] Sathye, M. 1999. Adoption of internet banking by Australian consumers: an empirical investigation. International Journal of Bank Marketing, 17(7): 324-334.

[32] Kim, D. J., Ferrin, D. L., \& Rao, H. R. 2008. A trust-based consumer decision-making model in electronic commerce: the role of trust, perceived risk, and their antecedents. Decision Support Systems, 44(2): 544-564.

[33] Chang, H.H., Chen, S.W. 2009. Consumer perception of interface quality, security, and loyalty in electronic commerce. Information \& Management 46(7): 411-417.

[34] Mattila M., Karjaluoto H., \& Pento T. 2003. Internet banking adoption among mature customers: early majority or laggards? Journal of Services Marketing 17(5): 514-528.

[35] Grove, W.M., Zald D. H., Lebow B. S., Snitz B. E., \& Nelson, C. 2000. Clinical versus mechanical prediction: a meta-analysis. Psychological Assessment 12(1): 19-30.

[36] Silver, N. 2012. The Signal And The Noise: Why So Many Predictions Fail-But Some Don't. Penguin: New York.

[37] Karelaia N, \& Hogarth RM. 2008. Determinants of linear judgment: a meta-analysis of lens model studies. Psychological Bulletin, 134(3): 404-426.

[38] Kahneman, D., \& Riepe, M. W. 1998. Aspects of investor psychology. Journal of Portfolio Management, 24(4): 52-65.

[39] Tversky, A., \& Kahneman, D. 1992. Advances in prospect theory: cumulative representation of uncertainty. Journal of Risk and Uncertainty, 5(4): 297-323.

[40] Szmigin, I., \& Foxall, G. 1998. Three forms of innovation resistance: the case of retail payment methods. Technovation, 18(6-7): 459-468.

[41] Gambardella, A., Khashabi, P., \& Panico, C. 2020. Managing Autonomy in Industrial R\&D: A Project-Level Investigation. Organization Science, 31(1): 165-181.

[42] Anderson, E., \& Weitz, B. 1989. Determinants of continuity in conventional industrial channel dyads. Marketing Science, 8(4): 310-323.

[43] Chua, R. Y. J., Ingram, P., \& Morris, M. W. 2008. From the head and the heart: locating cognition-and affect-based trust in managers' professional networks. Academy of Management Journal, 51(3): 436-452.

[44] Corts, K. S., \& Singh, J. 2004. The effect of repeated interaction on contract choice: evidence from offshore drilling. Journal of Law, Economics, and Organization, 20(1): 230-260. [45] Vanneste, B. S., \& Puranam, P. 2010. Repeated interactions and contractual detail: Identifying the learning effect. Organization Science, 21(1): 186-201.

[46] Vanneste, B. S., Puranam, P., \& Kretschmer, T. 2014. Trust over time in exchange relationships: meta-analysis and theory. Strategic Management Journal, 35(12): 1891-1902.

[47] Kleijnen, M., Lee, N., \& Wetzels, M. 2009. An exploration of consumer resistance to innovation and its antecedents. Journal of Economic Psychology, 30(3): 344-357.

[48] Tornatzky, L. G., \& Klein, K. J. 1982. Innovation characteristics and innovation adoption-implementation: a metaanalysis of findings. IEEE Transactions on engineering management, 29(1): 28-45.
[49] Foxall, G. R. 1993. The influence of cognitive style on consumers' variety seeking among food innovations. British Food Journal, 95(9): 32-36.

[50] Foxall, G. R. 1994. Consumer initiators: adaptors and innovators. British Journal of Management, 5(s1): 3-12.

[51] Ram, S. 1987. A model of innovation resistance. Advances in Consumer Research, 14(1): 208-211.

[52] Meuter, M. L., Bitner, M. J., Ostrom, A. L., \& Brown, S. W. 2005. Choosing among alternative service delivery modes: an investigation of customer trial of self-service technologies. Journal of Marketing, 69(2): 61-83.

[53] Rogers, E. M. 1995. Diffusion of Innovations (4th ed.). New York: Free Press.

[54] Mouilliet, D., Stolzenbach, J., Völker, T., \& Wagner, I. 2016. Robo Advisory in Wealth Management. Same Name Different Game - A Look at the German Robo-Advisor Landscape: Deloitte.

[55] Alter, A. L., \& Oppenheimer, D. M. 2008. Easy on the mind, easy on the wallet: the roles of familiarity and processing fluency in valuation judgments. Psychonomic Bulletin \& Review, 15(5): 985-990.

[56] Park, C. W., \& Lessig, V. P. 1981. Familiarity and its impact on consumer decision biases and heuristics. Journal of Consumer Research, 8(2): 223-230.

[57] Tversky, A., \& Kahneman, D. 1973. Availability: A heuristic for judging frequency and probability. Cognitive Psychology, 5(2): 207-232.

[58] Bandura, A., \& Walters, R. H. 1977. Social learning theory. Englewood Cliffs: Prentice-Hall.

[59] World Economic Forum. 2018. The Global Competitiveness Report 2018. Retrieved September 9, 2021, from https://www.weforum.org/reports/the-global-competitvenessreport-2018

[60] Stiftung Warentest. 2018. Die Maschine machts, Finanztest 08/2018: Stiftung Warentest.

[61] Earle, J. S., Spicer, A., \& Peter, K. S. 2010. The normalization of deviant organizational practices: wage arrears in Russia, 1991-98. Academy of Management Journal, 53(2): 218237.

[62] March, J. G. 1994. Primer on Decision Making: How Decisions Happen. New York: Simon and Schuster.

[63] Simon, H. A. 1959. Theories of decision-making in economics and behavioral science. The American Economic Review, 49(3): 253-283.

[64] Gennaioli, N., \& Shleifer, A. 2010. What comes to mind. The Quarterly Journal of Economics, 125(4): 1399-1433.

[65] Gilovich, T., Griffin, D., \& Kahneman, D. 2002. Heuristics and Biases: The Psychology of Intuitive Judgment. New York: Cambridge University Press.

[66] Kahneman, D. 2011. Thinking, Fast and Slow. New York: Farrar, Straus and Giroux.

[67] Tversky, A., \& Kahneman, D. 1974. Judgment under uncertainty: heuristics and biases. Science, 185(4157): 11241131

[68] D’Acunto, F., Prabhala, N., \& Rossi, A. G. 2019. The promises and pitfalls of robo-advising. The Review of Financial Studies, 32(5): 1983-2020.

[69] Milkman, K. L., Chugh, D., Bazerman, M.H. 2009. How can decision making be improved? Perspectives on Psychological Science 4(4): 379-383. 


\section{Appendices}

\section{Appendix 1. Client concerns about robo advisory: selected quotes from bank advisors}

Interviewee \# Statement

2 "There are two important questions. One question is, the robo advisory model, that sells and buys, that acts itself - of course, that requires trust - can it be hacked? Do you trust the algorithm? Do you feel comfortable letting the algorithm invest for you? It's like autonomous driving. I mean, do I want a car with a good navigation system that gives me tips, shows me where traffic jams are, but I am allowed to steer, or is the car driving? If it is really the case that decisions are executed by the algorithm, then trust needs to be there, in the data that the algorithm is fed with and how safe the algorithm is, an understanding of what can happen. That of course is a topic of concern for clients, if they decide to trust an algorithm."

3 "From a client perspective, the client for sure thinks that a person - an active portfolio advisor - is superior in making the one or the other investment decision. From a logical perspective it is the robo advisor that does better."

Appendix 2. Trust relationships, routines, and robo advisory: selected quotes from bank advisors Interviewee \# Statement

Trust relationships between clients and bank advisors

1 "[I have been advising some clients since 1999]. These clients, this may sound weird, they trust me blindly. If I tell clients to do something, they do it. They consider me part of the family. They know that we have been working together successfully for many years. Of course, investment performance also matters and there are better and worse years. But it's the cumulative investment performance over many years that counts. It's alright if there are a few bad years. It's like in a marriage - as they say, it's for better and for worse. [Also, in advisory relationships] you go through thick and thin together. But ultimately, that long connection, that personal [relationship you build], that is irreplaceable."

3 "Long client relationships mean that the client comes to you with all his/her financial issues - from investing money to credits, pension schemes, insurances, you name it. That the client trusts and knows that his/her contact person will share all of his/her professional expertise with him/her."

\section{Routines in personal interaction and robo advisory use}

3 "I personally doubt that a client who regularly interacts with bank advisors, talks with them will be up for the digital world with low interaction, where in the background computer-based decision processes are active. Clients have less influence there. When clients have close connection to [a contact person], they really appreciate that."

6 "Those clients who have a close connection with us, who enjoy our services, [they will stick to us]. It would be bad if it were different, I would say the goal of our bank is to create close connections to clients, a good cooperation in which both sides work together."

4 "[Why clients with longer history would be less likely to use robo advisory?] Well, because they are satisfied with us."

7 "If a client is used to always having a contact person, for example me, if s/he calls me, I help him/her, I can do everything for him/her. [...] S/he can always contact me. Then s/he has two contact persons. For a client, that is used to having a contact person, also specifically in APA, I think it is difficult for that client to receive support from a robot."

Appendix 3. Overview of key interview and interviewee facts

\begin{tabular}{|c|c|c|c|c|c|c|}
\hline \multicolumn{4}{|c|}{ Interview Facts } & \multicolumn{3}{|c|}{ Interviewee Facts } \\
\hline \# & Date & Type & Length (in Min.) & Position & Customer Segment Focus & Regional Focus \\
\hline 1 & 24.08 .2018 & Telephone & 45 & Bank branch manager & - & Munich City \\
\hline 2 & 24.08 .2018 & Telephone & 50 & Senior financial advisor & Private Banking & Munich City \\
\hline 3 & 28.08 .2018 & Telephone & 45 & Bank branch manager & - & Region South \\
\hline 4 & 28.08 .2018 & Telephone & 30 & Senior expert & Private Banking & Munich City \\
\hline 5 & 28.08 .2018 & Telephone & 40 & Regional head of portfolio advisory & - & Region South \\
\hline 6 & 30.08 .2018 & Telephone & 40 & Senior financial advisor & Private Banking & Region South \\
\hline 7 & 30.08 .2018 & Telephone & 40 & Senior expert & Private Banking & Region South \\
\hline
\end{tabular}

